\title{
DE LA DIVERSIDAD DEL SONETO
}

\section{ON THE VARIETY OF SONNETS}

\author{
Arcadio PARdo \\ Université Paris X Nanterre
}

\begin{abstract}
Resumen: El soneto ha incorporado una gran variedad de formas en todos sus componentes: metros, rimas, disposición de las estrofas, aspectos visuales, etc. Se propone este trabajo presentar las variantes más notables y también las más recientes. El soneto interpolado en un poema de dimensiones más amplias, como en el teatro, o en poemas líricos contemporáneos, permite sospechar su posible utilización como estrofa. La inmensa diversidad del soneto conduce también a plantear el problema de si debe considerarse aún como una forma fija.
\end{abstract}

Palabras clave: Soneto, variantes del soneto, soneto interpolado, sonetos experimentales, soneto-estrofa, forma fija.

Abstract: The sonnet has integrated a great variety of forms in all its components: meter, rhymes, lay-out of the stanzas, visual aspects, etc... This study proposes to present the most notable and recent variants. The sonnet, when integrated into a longer poem, like in theatre or contemporary lyrical poems, may suggest its possible use as a stanza. The wide diversity of the sonnet also leads to raise the question of whether it must still be considered as a set form. 
Keywords: sonnet, variants of the sonnet, interpolated sonnet, experimental sonnets, sonnet-stanza, set form. 
y advierta vuesarcé, señora Rosa, que le escribo, no más, este soneto porque todo poeta aquí se rozal. SOR JUANA INÉS DE LA CRUZ

Dios hizo al hombre y el hombre hizo al soneto ${ }^{2}$. CARlos EdMundo de ORY

\section{Continuidad y diversidad del soneto}

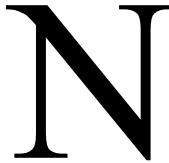

o es desconocida la múltiple diversidad que ofrece desde su aparición en castellano la forma «fija» del soneto. Los manuales de métrica suelen presentar las variantes más frecuentes, y en un trabajo más ambicioso Marcela López Hernández ha recogido lo más de las formas del soneto que los poetas han practicado desde su introducción ${ }^{3}$. Basta con recorrer el Índice General de este libro para comprobar la amplitud de las variantes. Es cierto que desde el siglo XVI hasta el XVIII se registra una regularidad que viene a quebrar el Modernismo con impulso renovador, hasta que en el siglo xx el soneto se impone de nuevo en su estructura más rigurosa, antes y después de la guerra civil española. Pueden recordarse los

$\overline{1}^{1}$ JJocoso, a la Rosa», en Obra selecta. Barcelona: Planeta, 1991, p. 87. La publicación reciente o la escasa difusión de algunas de las obras aquí utilizadas, o incluso la dificultad de poder disponer de otras, justifican que este trabajo presente bastantes textos copiados íntegramente. Algunos de ellos se encuentran difundidos en línea, en cuyo caso sus referencias se recogen en nota. Las palabras o versos que conviene poner de relieve se presentan en cursiva.

${ }^{2}$ Soneto vivo. Barcelona: Anthropos, 1988, p. 11. Sobre las innovaciones que la obra de Carlos Edmundo de Ory ha aportado a la poesía española, véase PoNT, Jaune: La poesía de Carlos Edmundo de Ory. Lérida: Universitat de Lleida, 1998.

${ }^{3}$ López Hernández, Marcela: El soneto y sus variedades (Antología). Salamanca: Ediciones Colegio de España, 1998. 
Sonetos espirituales de Juan Ramón Jiménez (1916), los Sonetos amorosos de Germán Bleiberg (1936), los de El rayo que no cesa de Miguel Hernández (1936), los de Espesa rama de Francisco Pino (1942), los Sonetos a la piedra de Dionisio Ridruejo (1943, «los catorce martillos del soneto»), los de Manuel y Antonio Machado, los de Manuel Altolaguirre, los de Gerardo Diego, los de Guillén, los de Lorca, los de Alberti. Y los de otros muchos.

Con la llamada «Juventud Creadora», en torno a José García Nieto, ya en la posguerra, se impone el soneto clásico entre los poetas de ese grupo que proclamó en su revista Garcilaso, «la segunda primavera del endecasílabo». El espléndido testimonio de la colección Adonais ofrece ejemplos de libros en sonetos como son los Poemas del toro de Rafael Morales (1943), y Edad de hombre de José Suárez Carreño (1943), y otros muchos fuera de la colección Adonais. Son libros de sonetos, impecables sonetos los más, los que componen los libros Los sonetos (1963) y Soneto vivo (1988) de Carlos Edmundo de Ory, algunos libros de Carlos Murciano, tales los Sonetos de la otra casa (1996), los de Música de la sangre (2002), los de Amatorio (2010), los numerosos incluidos en Algo tiembla (2010), y muchos más. Son de recordar igualmente algunos títulos de la tan espesa obra de Mario Ángel Marrodán, libros compuestos únicamente en sonetos, como Dossier de un cincuentón (1990) y Sono il sonetto Yo soy el soneto (2003). Pocos son los conjuntos editados en el siglo pasado que no contienen sonetos, tales como Arcángel de mi noche de Vicente Gaos (1943), Hoguera viva de Manuel Alonso Alcalde (1948), Tregua (1951) y La red (1955) de José García Nieto, Teatro real de Leopoldo de Luis (1957). Y en tiempo más próximo el titulado Guía lírica de Burgos de Carlos Frühbeck de Burgos (2001), el tembloroso y elegíaco Dolorido sentir de Luis López Anglada (2003), o Esta espina dorsal estremecida, Sonetos, de Sagrario Torres, publicado en 2007.

Se observa en general en estos libros citados un respeto común al canon clásico. Las novedades o variantes proceden más bien de la poesía hispanoamericana, impulsada por el Modernismo y sus herederos, sin que ello impida el cultivo también canónico del soneto en Hispanoamérica como es el caso de los 
poetas Leopoldo Lugones, Julio Herrera y Reissig o de Jorge Cuesta ${ }^{4}$, por no acumular otros nombres conocidos.

El cultivo del soneto en el xx ha planteado otro tipo de problemática. ¿Será la rigidez del soneto un impedimento para la libre expresión o, al contrario, esa rigidez puede favorecer su eclosión? Si «l'art est une contrainte», el soneto debe conducir a la consecución de la obra. Los poetas exponen con frecuencia esa tensión entre la rigidez de la forma y el contenido, confesando, en general, encontrar en el soneto, a pesar de sus exigencias, el lugar adecuado para plasmar sentimientos o ideas.

Los sonetos que los poetas dedican al soneto son muy numerosos desde el de Baltasar del Alcázar («Al soneto, vecinos, al malvado») hasta hoy, y pueden clasificarse según distintos criterios. Interesa aquí ver cómo el poeta se encara con esa forma, la anexiona a sí, la siente agónica o placentera. Ninguna otra composición o estrofa ha provocado tanta confesión del poeta al hacerlo continente de su pensamiento. Es muy conocido el de Juan Ramón Jiménez que expone esa preocupación:

En ti, soneto, forma, esta ansia pura copia, como en un agua remansada, todas sus inmortales maravillas.

La claridad si fin de su hermosura es, cual cielo de fuente, ilimitada, en la limitación de tus orillas 5 .

Vicente Gaos expresa rudamente esa agonía y su conformidad con la forma que le facilita el camino hacia la luz:

Mas, no, soneto, tú no me encadenas, conduces mi pasión, riges mi anhelo, cauce de mi hondo río en este suelo, lecho feliz, mi vida entera ordenas.

No me encadenas, me desencadenas, órbita, estrella mía, libre cielo,

\footnotetext{
${ }^{4}$ Cuesta, Jorge: Poemas y ensayos. México: Universidad Nacional Autónoma de México, 1964. Un estudio importante de los Sonetos de Jorge Cuesta es el realizado por Allaigre-Duny, Annick: L'écriture poétique de Jorge Cuesta: les Sonnets. Pau: Covedi-CDRLV, 1996.

${ }^{5}$ Sonetos espirituales, «Al soneto con mi alma». Soneto inicial.
} 
amor, errantes astros, sabio vuelo, música de la sangre por las venas.

La luz, la luz... Delante está el camino.

Por él iré hasta ti, por él espero poder precipitarme en mi destino.

Oh vida recta y fiel, así te quiero: recta, fiel, estelar, fuego divino, ciega flecha, universo verdadero ${ }^{6}$.

Ofrece este soneto una acumulación de atributos que el poeta ensalza progresivamente hasta erigir la composición a «universo verdadero»: cauce, lecho, órbita, estrella, cielo, amor, astros, vuelo, música, luz, recta fiel, fuego divino, ciega flecha. Comparables a estos atributos son los que ve en el soneto Blas de Otero quien ofrece en este que sigue, una serie de definiciones igualmente de excelsitud: «plumas de luz», «cárceles de mi sueño», «lenguas de Dios», «manos de Dios», etc.:

Estos sonetos son las que yo entrego

plumas de luz al aire en desvarío; cárceles de mi sueño; ardiente río donde la angustia de ser hombre anego.

Lenguas de Dios, preguntas son de fuego que nadie supo responder. Vacío silencio. Yerto mar. Soneto mío, que así acompañas mi palpar de ciego.

Manos de Dios hundidas en mi muerte. Carne son donde el alma se hace llanto. Verte un momento, oh Dios, después no verte.

Llambria y cantil de soledad. Quebranto del ansia, ciega luz. Quiero tenerte y no sé dónde estás. Por eso canto ${ }^{7}$.

${ }^{6}$ Soneto titulado «La forma», en Arcángel de mi noche. Madrid: Adonais, 1944. Otra referencia al soneto en la obra de V. Gaos se encuentra en «Soneto umbrío», Poesías completas. II, León: Col. Provincia, 1974, p. 197. Dice en él: «Te tendré que escribir, soneto umbrío, / y así podréis decir: ¡Literatura! / No poesía social, ¡vaya basura! / Pura música sí, concierto mío».

7 «Estos sonetos», en Ancia. Madrid: Visor, 1975, 33. Marcela López Henández lo incluye en su capítulo «Soneto a un soneto», El soneto, cit., p. 358. 
El que titula «Su último secreto» presenta el soneto como instrumento dócil en el que el poeta no encuentra trabas («para que dentro de él ardas, delires»):

El soneto es el rey de los decires.

Hermoso como un príncipe encantado, con una banda azul, cuadriculado para que dentro de él ardas, delires.

Es preciso que bogues raudo y gires entre sus olas y su muelle alzado; quede tu pensamiento destrozado cuando te lances de cabeza y vires.

Yo tengo en cada mano un buen soneto, como dos remos de marfil y oro. Yo conozco su íntimo secreto.

Es un silencio pronunciado a coro por un labio desnudo, blanco, inquieto y otro labio sereno, abril, sonoro ${ }^{8}$.

Mario Ángel Marrodán interpreta el soneto como ofrenda a la vez de laboriosa faena y de encuentro feliz, «hogar de los poetas». Le denomina fervorosamente «Son total, voz profunda, relámpago, combate, verbo del corazón». Es el titulado «Soneto en son total». Su terceto final termina así:

Del verso a verso en las catorce vetas virtud de un ejercicio atormentado, perfección del hogar de los poetas 9 .

Este poeta inventa el verbo «sonetear» que viene a ser como una conducta íntima, como una manera de fundirse en la forma, «sometiéndose a su disciplina» y saliendo victorioso:

Yo soneteo, sí, yo soneteo.

Quiero sonetear con el soneto.

Sé que a su disciplina me someto

y a la ley de la rima la rastreo.

$\overline{8}$ «De todos mis sonetos», «Su íntimo secreto», en Expresión y reunión. Madrid: Alianza, 811, 1985, p. 223.

${ }^{9}$ «Soneto en son total», en Sono il sonetto Soy el soneto, Castiglione di Sicilia, 2003, p. 7. 
Lo bello de lo malo y de lo feo

bajo el arco triunfal de un buen cuarteto

sé discernir. Me encanta el vericueto,

pues me sirve de trampa y de recreo.

Va el siguiente. Es terceto. Es el primero

de dos a componer, y lo que espero

salga a la luz como una carta al cielo.

Pulo la joya del tesoro entero

con un endecasílabo modelo

Llegamos al final. Fírmalo hélo ${ }^{10}$.

En otro lugar el poeta crea otro verbo: «ensonetarse»:

Pues si hay que someterlo, lo someto, $\mathrm{y}$ a la pasión del canto me ensoneto ${ }^{11}$.

«Sonetear» se refiere al ejercicio de escribir sonetos. «Ensonetarse» traduce la voluntad de investirse en la forma, voluntad de dedicación. Para, en fin de cuentas, reconocer una contradicción, que

Del soneto yo sé que no sé nada ${ }^{12}$.

En otra dirección se encuentran las referencias de otros dos poetas. La primera en Soneto vivo de Carlos Edmundo de Ory, que recuerda

cuántas veces metí el dedo supersónico

en el cohete de un soneto ${ }^{13}$

siendo el soneto así como una fuga espontánea, como exhalación incontenida y la creación más alta del hombre: «Dios hizo al hombre y el hombre hizo al soneto ${ }^{14}$. Se cierra esta serie de citas con ésta última que procede de la antología de la obra del poeta José Manuel de Lara, y que dice así:

\footnotetext{
${ }^{10}$ Una carta de luz, ibid., p. 8.

${ }^{11}$ «Abrepáginas», ibid., p. 8.

${ }^{12}$ «Ley del soneto», ibid. p. 11.

13 «Ovario materno», en Música de lobo. Barcelona: Galaxia, 2003, p. 213.

14 «Oración», Soneto, cit., p. 11.
} 
El hombre que ahora soy se resiste a contaros su vida en este breve milagro de un soneto ${ }^{15}$

que en cierto modo se acerca a la idea de Carlos E. de Ory de que el soneto viene a ser algo como relámpago inesperado, cohete o milagro que resplandece. Es de notar que esta especie de atracción que el soneto ejerce, deja traslucir como una necesidad de justificación. Como si el soneto exigiera razonar su empleo, actitud inaudita en otro tipo de composiciones o de estrofas. No es posible no ver en ello también algo como un contagio generacional.

\section{La rima}

No procede registrar aquí las numerosas variantes que el soneto ha admitido y admite en el dominio de la rima, en cuanto a su disposición en las estrofas, el empleo aleatorio de las mismas, a su utilización parcial en la composición o la ausencia total en los llamados sonetos blancos. Sí recordar la virtuosidad que han demostrado algunos poetas del pasado utilizando, en algunos sonetos, rimas en las que solamente varía la vocal tónica: Quevedo ha escrito varios con estas características. Pueden verse, por ejemplo, «Prefiere la hartura y sosiego mendigo a la inquietud magnífica de los poderosos» («Mejor me sabe en un cantón la sopa») ${ }^{16}$ cuyas rimas son en -opa, y -apa en los cuartetos y en -ipa y -epa en los tercetos; «Felicidad barata y artificiosa del pobre», cuyas rimas son en -ucho y -echo en los cuartetos, $y$ en -acho e -icho en los tercetos ${ }^{17}$. O este otro titulado «Pronuncia con sus nombres los trastos y miserias de la vida $\rangle^{18}$ en el que los cuartetos riman en -aca y -oco, y los tercetos en -uca y -eca («La vida empieza en lágrimas y caca»). Otros

${ }^{15}$ Retrato apresurado: antología poética. Huelva: Consejería de Cultura, Delegación de Huelva, 2003.

${ }^{16}$ Obras completas, I, Poesía original. Edición de José Manuel Blecua. Barcelona: Planeta, 1963, p. 566.

${ }^{17}$ Ibid., p. 573.

${ }^{18}$ Ibid., p. 577. Pueden verse también los titulados «Aquí fue Troya de la hermosura» (p. 589), «Despídese de la ambición y de la corte» (p. 603), «Gabacho tendero de zorra continua» (p. 611), el que empieza con el verso «Volver quiero a vivir a trochemoche» (p. 620), y probablemente otros más. 
del mismo emplean rimas en ate-ete-ite-ote (Soneto «Vieja verde...»), en ajo-eja-ojo-ujo (Soneto «Pinta el «Aquí fue Troya»), en aza-ezo-oza-uza (Soneto «Despídese de la ambición...)», en eces-ices-oces-uces (Soneto «Leyes bacanales...»), y en acheeche-oche-uche («Soneto») $)^{19}$.

También se encuentran sonetos de este tipo en la obra de Sor Juana Inés de la Cruz, como en el tercer soneto «Jocoso, a la Rosa» que encabeza este trabajo y cuyas rimas son en -afa, -ufo para los cuartetos, y -afe y -ofe para los tercetos («Vaya con Dios, Beatriz, el ser estafa») ${ }^{20}$.

Algunos de los sonetos de Petrarca tienen rimas semejantes, pero no en la totalidad del soneto sino sólo en dos estrofas como en estas que siguen en las que se han utilizado rimas en -elli y -alli:

Il cantar novo e "l pianger delli augelli in sul dí fanno resentir le valli, e 'l mormurar de' liquidi cristalli giú per lucidi, Fieschi rivi et snelli.

Quella ch'à neve il volto, oro i capelli, nel cui amor nun fur mai inganni né falli, destami al suon delli amorosi balli, pettinendo al suo Vecchio i Bianchi velli ${ }^{21}$.

No es posible afirmar que estos sonetos sean un precedente a los arriba citados. Tampoco se puede asegurar que este empleo por parte de Petrarca sea intencionado. Como tampoco lo es la utilización en castellano de rimas derivadas de participios en -ado, -ada, -ido. Esta modalidad de rimas se ha abandonado posteriormente; y si alguna vez aparece, se trata de un empleo puramente casual, no intencionado, como en el soneto «Hablando claro» de Carlos Murciano en su libro Como un agua escondida; en él se utilizan rimas en -aras / -eras en los cuartetos:

${ }^{19}$ Ibid., pp. 588, 589, 603, 609 y 620 .

${ }^{20}$ Obra selecta, cit., pp. 87-88.

${ }^{21}$ Soneto 219 del Canzoniere. Otros sonetos emplean rimas de este tipo como el 179 («Geri, quando talor meco s'adira») que emplea en los cuartetos rimas en -ira y en -era. El 291 («Quand'io veggio dal ciel scender l'Aurora») rima en -ora y -oro los cuartetos y en -uri los versos 9 y 11 . Utilizo la edición bilingüe italiano/francés de Pierre Blanc. Paris: Garnier, 1989. Soneto 219 en p. 364; el 179 en p. 316. El 291 en p. 456. Pueden encontrarse otros del mismo tipo. 
Las cosas claras, Dios, las cosas claras. ¿Acaso te pedí que me nacieras, que de dos voluntades verdaderas, de barro y llanto, Dios, me levantaras?

¿Acaso te pedí que me dejaras en mitad de la calle -en las aceras se apiñaba la vida-, y que fueras y que con tu desdén me atropellaras?

Las novedades más atrevidas en nuestro tiempo son las que aparecen en los sonetos monorrimos; Marcela López Hernández incluye en su libro dos de Ángel Urrutia Iturbe (1933-1994) con rima única en -ales. Uno existe, más novedoso, que tiene la particularidad de usar no sólo de la modalidad de monorrima sino de utilizar una misma palabra final en todos los versos del soneto. Es el soneto titulado «Nada», de Francisco Pino, que termina los catorce versos precisamente con la misma palabra nada:

No amo las letras, no me dicen nada, amo la vida vida que cual nada se erige hermosa en luz que es también nada, hermosa por ser luz y por ser nada.

Amo del hombre la ingeniosa nada que es nada y es el todo y a esa nada que en social forma no traduce nada y que llamo familia, mesa o nada;

a esa nada que estómago de nada, lo firme, lo seguro, techo y nada, nada por cima por debajo nada,

y que en planeta se halla. Tierra es nada o el conjunto final. Mas en la nada

la Tierra es todo, todo lo que es nada ${ }^{22}$.

Las experiencias de Francisco Pino le han conducido a indagar nuevas formas expresivas y merece se recuerde el intento de utilizar monosílabos en rima, esporádicamente, o con utilización frecuente como en el soneto «El corazón» cuyos cuartetos son los siguientes:

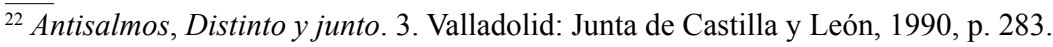


¿Qué? ¿de ese qué qué queda? ¿Queda o no qué? ¿Qué qué? Un qué que no se sabe, sí, que no. Que ya no, nunca más. Y ahí por siempre ya ese qué que harto no es $o$

ni es y, ni significa que es justo un no que en sí se queda ni flor, ni luz, $n i$ tan siquiera euforia y es más, es $o h$ que al sentido convierte en Potosín ${ }^{23}$.

\section{Polimetría}

Tampoco es de este lugar registrar todas las variaciones que el soneto ha admitido y admite en cuanto a los metros empleados: los endecasílabos de rigor, los de versos menores de hasta una sola sílaba gramatical, los de versos mayores de hasta dieciocho o veinte sílabas, la polimetría. Un soneto de una sola sílaba gramatical es el titulado «SON E TO» que Francisco Pino incluyó en su libro Solar, publicado en 1969 que se cita más abajo en el apartado Variantes recientes del soneto ${ }^{24}$.

Se recogen en cambio a continuación los casos o novedades que merecen mayor atención.

Sonetos lipogramáticos: sin sinalefas, sin hiatos, sin vocales, con sólo una vocal

Un texto lipogramático no es actualmente una novedad desde que Francisco de Navarrete y Ribera escribió en 1640, su novela Flor de Sainetes, sin utilizar la letra a. Más próximo en el tiempo, Enrique Jardiel Poncela publicó, entre 1926 y 1927, cinco relatos lipogramáticos, prescindiendo cada uno de ellos de una de las cinco vocales, como El chofer nuevo en el que no aparece la letra a, y Un marido sin vocación, en el que no aparece la letra e.

Aunque también en Francia hubo antecedentes, la novela de George Perec La Disparition publicada en 1969 y en la que no figura la letra e, causó sorpresa y curiosidad, traducida después al español con el título de El secuestro, sin usar la letra a. El mismo George Perec publicó poco después, en 1972, otra novela, Les Revenantes, en la que sólo aparece la letra $e$. La curiosidad

${ }^{23}$ Ibid., III, pp. 353-354.

${ }^{24}$ Ibid., p. 135. 
que estos ensayos han despertado ha pasado al cine y, en efecto, en la película Misery (de Rob Reiner, 1990) la protagonista secuestra a un escritor y le ordena escriba una novela sin la letra e. En poesía, ensayos de este tipo son más bien tardíos y marginales y no parecen haber provocado el gusto de los poetas. Hoy circulan algunos en la red, escritos por autores adscritos a grupos que al parecer intercambian sus creaciones y sus opiniones al respecto. En cambio se observa cierto afán en esos grupos por difundir los sonetos lipogramáticos que han escrito en época reciente. Pueden citarse los «Cinco sonetos sin una vocal» de Martín de San Martín; se copia a continuación solamente, a modo de ejemplo, el primer cuarteto de cada uno de ellos:

soneto sin la a

El sol en el cenit tiene esplendores, tiene hermosos crepúsculos el cielo; el ruiseñor sus trinos y su vuelo; corriente el río, el céfiro rumores.

soneto sin la e

Con ojillos oscuros, luminosos, ambas tan blancas como dos palomas, cruzando prados y salvando lomas hoy las vi con dos pícaros gomosos.

soneto sin la $i$

Blanca como la luz que el alba arroja, pura como la flor que el aura mece, por ella culto, pero noble, crece, este amor que locura se me antoja.

soneto sin la o

Gime desamparada Magdalena, víctima de pesares que la matan; y sus pupilas el raudal desatan de lágrimas que causan tanta pena.

soneto sin la $u$

Soneto me pedís en donde omita la postrera vocal del alfabeto; y en dos por tres pergeñaré el soneto si no se llega a enmarañar la pita ${ }^{25}$.

$\overline{{ }^{25} \mathrm{Se}}$ encuentran en línea: http://www.albaiges.com/eulogologia/lipogramas/cincosonetosvocal.htm. 
Mayor dificultad representa un soneto en el que solamente aparece una vocal, como este que sigue, de Jonh A. Redhair en el que utiliza la vocal e aunque no exclusivamente, con sus estrofas distribuidas en $4+4+4+$ pareado:

El pesebre, el esqueje, el referente, el deje, el neceser, el requeté, dependen de este ente referente que es la célebre y leve letra $\mathrm{E}$.

Se crece en tres esquejes hacia el este que penden de esa especie de eje breve. Es peine que entremete al arcipreste, y es épsilon endeble que se embebe.

Con la E el petimetre se estremece, ese nene entre peces se entretiene, el ser que crece a veces se enternece, y el perenne gerente se previene.

Que la E tiene que verse es menester en el debe, en el tres y en el beber ${ }^{26}$.

Otro ejercicio emparentado con el de la eliminación de vocales consiste en crear sonetos que evitan la sinalefa y/o los hiatos. Puede citarse el «Soneto -sin sinalefas- ante una calavera que tuve como huésped varios días en mi casa», de Sagrario Torres. Forma parte ese soneto del libro ya citado Esta espina dorsal estremecida, Sonetos. Explica la autora en nota que el soneto lo escribió en 1969 y que nunca había encontrado ninguno sin sinalefas en la poesía española de todos los tiempos ${ }^{27}$. Es el que se copia a continuación:

Esto fue vida, terrenal latido; hoy, sarcástico gesto belicoso.

Por defender su tuétano gozoso, ¿con qué furor habrían embestido

sus frenéticos dientes el tejido del gusanil ejército vicioso,

${ }^{26}$ En línea: http://www.elreinodelsoneto.blogspot.com/2011/.../la-letra-e-sone. «La letra E», en «El soneto diario», 31 de Marzo de 2011. Soneto 345.

${ }^{27}$ Esta espina dorsal estremecida, Sonetos. Madrid: Ediciones Torremozas, 2007, p. 72. 
si pudieron triunfar del poderoso demoledor martillo del olvido?

En mi casa vivió la tan callada, dándome su lección fatal y cierta como mejor no pueden los más sabios.

En tanto que la tuve de prestada -y porque viva fue su boca muertala puse flores donde fueron labios.

La curiosidad me ha llevado a descubrir otros sonetos sin sinalefas más recientes como son los siguientes: «Hacer un soneto sin sinalefas», firmado por Artesana ${ }^{28}$, «Navega mi soneto» de Fabiana Piceda, «Porque gustan los retos especiales» de Luis Pérez e «Hiato, sinalefa son hermanos» de Adriana Marta Marqués. Luis Pérez ha compuesto otro que titula «Sin hiatos ni sinalefas $\rangle^{29}$.

Me han llamado la atención algunos títulos de obras de publicación reciente en las que pensé encontrar «nuevas novedades», como estos que siguen:

- Antología del soneto fúnebre por Brígido Redondo; selección arquetípica, Fredo Arias de la Canal, en 2003;

-Antología del soneto oral-traumático, tanático, cósmico y erótico en Cuba, por el mismo editor en 2008;

- Antología del soneto oral traumático, homosexual y lírico de Rubén Failde Braña, en 2008;

- Antología del soneto oral-traumático, cósmico y erótico de Francisco Henríquez, publicado en México por el Frente de Afirmación Hispánica en 2009.

Pero estas obras de títulos tan llamativos no contienen sonetos con desvíos formales aunque pueden tratar temas de mayor atrevimiento que los que se encuentran en la poesía heredada de los poetas precedentes.

\footnotetext{
${ }^{28}$ En línea: http://www.poesiaartesana.com/ de 20 de enero de 2013. Los otros sonetos citados se encuentran igualmente en línea.

${ }^{29}$ Pueden verse en línea en la misma dirección: http://www.poesiaartesana.com/
} 


\section{Sonetos de menos o de más de catorce versos}

Es muy conocido el soneto de trece versos de Rubén Darío en Cantos de vida y esperanza que, con su final en cascada, disimula el no respeto de la forma ${ }^{30}$. Pero existen otros en los que la disposición de los versos resulta más novedosa. Es el caso del de Luis G. Urbina titulado «Alborada» y que se compone igualmente de trece versos distribuidos en dos cuartetos seguidos de un quinteto. Aunque el poeta no lo denomina soneto, se reconoce la proximidad a esa forma en la distribución de las rimas de los cuartetos que curiosamente se mantienen además en el quinteto final:

Blanca de leche sonrosada. Apenas una línea de azul empalidece el gris del horizonte. El mar parece inundación de jugo de azucenas.

Hay en las nubes blancas y serenas un tímido rubor que resplandece, y sobre el carmen celestial, florece el lirio de un lucero. En las morenas

verduras un bohío se emblanquece; fulge una orla de espuma en las arenas, un ocre resplandor se aviva y crece; rompe la luz en triunfo sus cadenas y se deshace en púrpura. Amanece ${ }^{31}$.

En cambio el titulado «Vespertina VIII», también de Luis G. Urbina, se compone de dos cuartetos seguidos de dos versos, separados de los dos siguientes y de un terceto final. El conjunto de quince versos presenta, como el anterior, sólo dos rimas consonantes con el esquema $\mathrm{ABBA} / \mathrm{ABBA} / \mathrm{AB} / \mathrm{AB} / \mathrm{ABA}$ :

Te vas por el camino polvoriento que en la triste llanura se dilata, mientras el gran crepúsculo de plata se oscurece como un presentimiento.

\footnotetext{
${ }^{30}$ Sobre este soneto véase DunY, Annick: «Rubén Darío: el soneto de trece versos». Les Langues Neolatines, 1995, 294, 3er trimestre, pp. 107-119.

${ }^{31}$ Urbina, Luis G.: Poesías completas. II. Méjico: Porrúa, 1964, p. 116.
} 
Calladamente vas, a paso lento, por la penumbra gris. Y se desata el aire de la noche. - Adiós, ingrata!gime, en la voz del aire, el pensamiento.

Me despedí sin llanto y sin lamento. -Qué muda está la pena que me mata-

- Ya estoy solo otra vez... -digo, y me siento a esperar el instante que rescata

de toda angustia y todo sufrimiento... $\mathrm{y}$ aun [sic] te columbro, en el confín de plata, marchar por el camino polvoriento ${ }^{32}$.

\section{Sonetos con disposición no tradicional}

No escasean los sonetos que han sido tratados con distribución no regular de los versos, aun conservando el número de catorce requeridos. Se trata de una modalidad relativamente reciente. Ya son conocidos algunos sonetos invertidos con distribución de $3+3+4+4$. Marcela López Hernández los denomina «Sonetos al revés» y reproduce uno de Ricardo Carrasquilla (1827-1885) y otro, en octosílabos, de José Bergamín ${ }^{33}$. Actualmente otros poetas los crean con intención renovadora $\mathrm{y}$, como este que sigue, de autojustificación:

En busca de solaz y alternativa, rompí la tradición y los libretos, $\mathrm{y}$ estando en sana audacia creativa,

le di un nuevo diseño a los sonetos, con un revés actual, de abajo a arriba; trocando a los cuartetos por tercetos.

No es este -aunque parezca entre sus malesel caos de un poeta en ejercicio, ni es muestra de locura o de desquicio, sino que es una opción de liberales.

Empiezo con los seis versos finales y acabo con los ocho del inicio,

${ }^{32}$ Ibid, p. 72.

${ }^{33}$ El soneto, cit., pp. 40 y 41. 
y luego de aplicar este artificio:

Por gracia de Jesús, se oyen geniales!

Su autor es Enrique Quiroz Castro, de Pira, Perú. Ha fechado el soneto el 23 de febrero de $2006^{34}$.

Este que sigue es de Anabil Cuadra. Aunque los seis versos primeros aparecen en dos grupos de tres, en realidad están constituidos por tres pareados, AA-BB-AA:

Se quedó invertido mi soneto

por capricho que vieran cuanto aprieto

es escribir de patas a cabeza.

Parece dar un poco de pereza

para inspirar un rítmico terceto

ipero lo ves! pasamos al cuarteto.

¡Qué travieso poema puedes ver!

adornado de rimas al versar,

sin perder su armonía por crear

estrofas al revés y sin caer.

Mira cuán divertido que es hacer que su cuerpo se quede sin variar en locuaz posición, y así pensar:

¡no es difícil!, es cosa de querer ${ }^{35}$.

De publicación muy reciente es el X, soneto invertido, polimétrico y blanco, que forma parte del libro Lectura del mundo de Enrique Villagrasa, cuyo inicio es: «Facebook lee antes la voz del poeta» ${ }^{36}$.

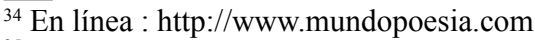

${ }^{35}$ En línea en la dirección: http://www.mundopoesia.com Pueden encontrarse otros sin esfuerzo. Véase éste, muy reciente encontrado igualmente en: http://www.poemas-del-alma.com. Su autor Jareth Cruz, que es pseudónimo. Soneto publicado el 25 de noviembre de 2012, perteneciente al conjunto Poemas del alma. SUFRIENDO POR TI IV (Soneto invertido): «He deseado acabar con mi vida / desde ese mismo día en que te fuiste / porque me afectó mucho tu partida. / Sigo creyendo que esa es la salida / para ya no sentirme solo y triste / y con esta profunda y gran herida. / Amor ¿Por qué tuviste que dejarme? / si supieras lo mucho que me duele / mi corazón sólo preguntar suele, / mientras que yo quisiera suicidarme. / Vuelve a mis brazos, vuelve a regalarme / de tu perfume que tan rico hüele. / No permitas que al otro mundo vuele. / Mi amor; ven por favor a rescatarme.» Puede citarse también el titulado «Aquí están», de María Bote, fechado el 30 de octubre de 2011.

${ }^{36}$ Villagrasa, E.: Lectura del mundo. Sevilla: Edición de La Isla de Siltolá, 2014, p. 35. 
Los sonetos con disposición no tradicional pueden presentar, además de los señalados como invertidos, diferentes estructuras, siendo una de ellas la que utiliza la distribución de $4+4+4+2$; las tres primeras estrofas pueden ser serventesios o cuartetos aconsonantados y los dos versos finales formando o no pareado y con rima ya utilizada en alguna estrofa anterior. He aquí uno de Carlos Edmundo de Ory en el que se observa que el pareado final utiliza una rima de la segunda estrofa. Hay, además, la alternancia de la rima en -asta/-asto, aunque probablemente no conscientemente intencionada:

SONETO ESCRITO EN LA TABERNA

Es la noche y me pongo a meditar en estos seres que construyo en lo alto de mi alma maníaca y del mar que salta en el amor y en el asfalto

Voy por las calles lleno de intención lleno de nuevas llamas en canasta y me sostiene siempre una canción que nadie entiende y ¡bueno! a mí me basta.

Pido a los seres algo que es tan vasto que no les cabe en la espaciosidad. Nadie sabe que tengo un fuego casto que arde en la Iglesia de la Libertad.

Voy por las calles lleno de intención y me sostiene siempre una canción ${ }^{37}$.

Otro del mismo poeta, «La Virgen del Aprisco», adopta la estructura $5+5+2+2$, o sea, dos quintetos con distinta distribución de rimas y un serventesio presentado con los versos separados de dos en dos:

La lana de la luna la cieluna

el humo que en la loma se amotina

el traje del paisaje hecho de una

materia enmarañada mortecina

último atisbo de su sombra hombruna

${ }^{37}$ El desenterrador de vivos. Barcelona: Galaxia Gutemberg, Círculo de lectores, 2006, pp. 46-47. 
Grito despavorido del arado

los bueyes vesperales van huyendo.

y el labriego feraz los persiguiendo

arando dando sin saber quién siendo

los bueyes va guiando sosegado

Baja la Virgen por el dulce Aprisco

trae una cesta llena de bellota

La lumbre enciende con amor y cisco

y el humo por el aire quieto flota ${ }^{38}$.

En el titulado «Poder» modifica la forma final, de modo que el pareado está formado por los versos 9 y 10, pero no separados tipográficamente de los dos siguientes. Los dos versos finales recogen rimas de los versos 12 y 11 . Su estructura es, pues, la de $4+4+4+2$. Se copia la estrofa 3 y los dos versos finales:

Rindo culto a la vida múltiple y a lo amable dejándome empapar de todo permeable como una esponja empezando por el pelo hasta los pies descalzos y nada me hace daño

Nacer para morir no es más que darse un baño en el océano infinito del anhelo ${ }^{39}$.

Parecida distribución tiene el titulado «Esperas que el efecto...», de Amador Palacios, compuesto de tres cuartetos y dos versos finales que difieren respecto al de C. E. de Ory, en que estos dos riman con los versos del cuarteto que precede ${ }^{40}$.

El lector encontrará sin gran dificultad otros ejemplos de sonetos en forma no tradicional en la poesía contemporánea, como

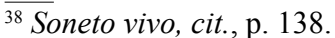

${ }^{39}$ Ibid., p. 34.

${ }^{40}$ «Esperas que el efecto...»: Esperas que el efecto del canuto / se disipe y así coger el coche / sin problemas, llevándolo en la noche / como una góndola por mar de luto. / Luto al irse el verano, al irse aquello / que llenaba las horas de potencia / lumínica, mesura, somnolencia / de colchas blancas (siempre un perfil bello). / Oyendo de Messiaen la sinfonía, / y aguardando que el globo quiebre el sino, / esperas, con el gato, hallar un fino / momento que sentir al fin del día, / estética emoción al ver la estría / del sol en horizonte peregrino.»

Palacios, Amador: Licencias de pasaje. Ciudad Real: Dip. Prov., Col. Ojo de Pez, 2007, p. 23. 
en el libro Deseo de la luz, de Ignacio Caparrós Valderrama, cuyos sonetos VI, IX, X, XI, XII, XVI de la primera parte («Cautiverios») y XXIV, XXVI, XXVIII, XXXII, XXXIV, XXXVI, XXXIX de la tercera («Desazones»), tienen unos la estructura $4+4+6$, otros la de $4+4+4+2$ formando o no los dos últimos versos un pareado. He aquí uno de la primera de las estructuras señaladas. Los cuartetos respetan la forma tradicional. Les sigue un sexteto con rimas alternadas que también pudiera haber presentado como dos tercetos tradicionales:

Debiste haber previsto tanto hastío, tanta desolación, tan vil ralea, ciega no más luchar en la pelea del fuego contra el ascua, el polvo frío.

Debiste haber sabido lo que es mío, la verdad de la luz con que se crea de lo más ruin, la más hermosa tea que alumbra en lo profundo lo baldío.

Mas no, tú no. Que vas cantando ciego, negando mi presencia en cada ahora.

Te basta arder, quemarte en lo que niego a cada entrega, a cada asoladora combustión del instante en llama. Y luego me dices que es mi cera la que llora ${ }^{41}$.

Emparentados con estos sonetos de distribución no regular de las estrofas pueden ser dos de Dionisia García en su libro Señales, titulados «Imprevisiones» y «De lo natural», que distribuyen sus versos en grupos de $4+3+3+4$, o sea, con los tercetos en posición media, por lo demás sin rima y sin medida regular ${ }^{42}$. Una variante más atrevida se encuentra en un soneto de Justo Alejo que utiliza a la vez palabras, o sílabas, o letras en mayúsculas, y una distribución de los versos que no aparece en los sonetos conocidos: 4+1+4+1+4. Algunas palabras se desprenden del verso y aparecen sangradas y colocadas en la línea siguiente. No conozco ningún texto en el que este poeta razone su modo de hacer. El soneto que sigue es el titulado «Por $\mathrm{H}$ o por $\mathrm{B} »$ :

${ }^{41}$ Caparrós Valderrama, I.: Deseo de la luz. Algeciras: Col. Bahía, 1999, p. 26.

${ }^{42}$ García Dionisia: Señales. Sevilla: Renacimiento, 2012, pp. 36 y 64. 
Vamos dESPACIO YA a Venta de BAÑOS cuando la tarde ponga trenes a la estePA Se encenderá el BALAR de OTROS rebAÑOS y HABRÁ Ni-eve en la FAZ de ANAcoreta VAGOS desPACIO YA a VENTA DE BAÑOS

Nieve de ti y más ni-eve de marías que no faltarán plumas migratorias al velorio sin de tardes de aves frías donde disuelve el viento otras historias ni aves de ti ni-a ve s de $\mathrm{m}$ arí $\mathrm{A}$ OTRAS, OSTRAS, HOSPICIOS, HOSPITALES obliterada raíz cuadrada del sufragio y que te vi venir CANTANDO TREINTA

IGUALES

PLAGIOS DE TI: IMPOSIBLE: EXACTO:

PLAGIO $^{43}$.

La utilización de mayúsculas y/o de caracteres tipográficos distintos (palabras en negrita, por ejemplo) tiene un antecedente, muy probablemente desconocido por Justo Alejo, en los «Sonnets dénaturés» de Blaise Cendras, incluidos en su obra $D u$ monde entier au coeur du monde ${ }^{44}$. Estos sonnets dénaturés son tres; el primero «OpOetic» presenta la vocal o siempre en mayúsculas, además de una $\mathrm{O}$ desmesurada en el «verso» final; el segundo «Académie Médrano» utiliza caracteres diversos y una llave corchete; el tercero «Le musickssme», mayúsculas y una presentación tipográfica no tradicional. No se respeta en ellos la distribución de estrofas, ni el número de versos del soneto; la rima está ausente. Los tres estás fechados en noviembre de 1916.

\section{Sonetos con versos o fragmentos de versos repetidos}

Conviene señalar un soneto del siglo XVI francés que repite el primer cuarteto íntegro en el segundo y resulta ser un caso

\footnotetext{
$\overline{43}$ Alejo, Justo: Poesía 2. Valladolid: Fundación Jorge Guillén, 1997, p. 434.

${ }^{44}$ Paris, Denoël, 1947 y varias ediciones sucesivas, pp. 111-115. La edición más reciente es la de Poésie Gallimard.
} 
único. Es el Soneto [LXXIX] del Second livre des Amours, de Ronsard ${ }^{45}$ :
Estrofa 1 :
Dites, maitresse, hé que vous ai-je fait!
Hé pourquoi, las!, m'êtes-vous si cruelle?
Ay-je failli de vous être fidèle,
Ay-je envers vous commis quelque forfait?

\begin{abstract}
Estrofa 2:
Dites, maitresse, hé que vous ai-je fait!

Hé pourquoi, las!, m'êtes-vous si cruelle?

Ay-je failli de vous être fidèle,

Ay-je envers vous commis quelque forfait?
\end{abstract}

Esta experiencia no ha tenido consecuencias en la poesía posterior francesa y tampoco se pueden aportar casos semejantes en poesía española. Sí, sin embargo, una multiplicidad de palabras iniciales o versos enteros que se repiten en otros versos del soneto. Se encuentran sobre todo en poetas de épocas recientes en las que la obra poética brota con una conciencia de libertad de expresión amplia y aceptada. Marcela López Hernández, que clasifica estos sonetos como sonetos con epanáfora, presenta uno de Quevedo titulado «Epitafio de una dueña, que idea también puede ser de todas $\gg{ }^{46}$. No se trata, por lo tanto, de una variedad nueva. Sí, en cambio, se observa que lo que en Quevedo es juego, en los poetas de nuestro tiempo o de épocas próximas, esta utilización de palabras o versos repetidos adquiere un significado poético que parece legítimo señalar. La repetición de los términos, la variación de los mismos de una a otra estrofa, aportan al poema una insistencia, una gravedad que sobrepasa el mero ejercicio y añade, en cambio, emoción, belleza, y densidad.

Es de sospechar que esta libertad de repetir palabras o versos enteros procede de la poesía modernista hispanoamericana, aunque tenga antecedentes remotos en los cosautes antiguos con

\footnotetext{
${ }^{45}$ Ronsard: Euvres complètes. Paris: Pléiade, Gallimard, 1993, I, p. 280.

${ }^{46}$ López Hernández, Marcela: El soneto y sus variedades, cit. p. 190. Es el que empieza con este cuarteto: «Fue más larga que paga de tramposo; / más gorda que mentira de indiano; / más sucia que papel en el verano; / más necia y presumida que un dichoso». El cuarteto siguiente, y los versos 9 y 11, empiezan igualmente con el adverbio más.
} 
ramificaciones en la poesía contemporánea, como en el «Llanto por la muerte de Ignacio Sánchez Mejías» de García Lorca o en «Barado del Paraná» de Rafael Alberti. La repetición de versos se encuentra ya, en efecto, en el soneto «Entre dos lentes. En un establecimiento fotográfico», de Salvador Díaz Mirón, que copia en los dos versos finales los 3 y 4 del primer cuarteto, con la particularidad de que, además, el soneto se construye solamente con dos rimas. Los versos repetidos son versos contiguos y se repiten de dos en dos:

Bruno el sombrero que a lucir campea con alto moño y superior plumaje.

Faz que vela su olimpico linaje y que de negro el tul raya y puntea.

Azabache tejido el noble traje, y al cuello en un listón rica presea: adamantino aljófar que chispea en dos aros que intrican maridaje.

Al pecho y relumbrando en el ropaje, áurica soga. La beldad ladea el torso, mas no elude mi espionaje.

Y con gesto hermosísimo florea faz que vela su olímpico linaje y que de negro el tul raya y puntea ${ }^{47}$.

En este otro soneto, «A ti», del mismo, los versos 7-8 se repiten en 13-14, versos que recuerdan las palabras de Ruy Blas en el drama de Victor Hugo: «ver de terre amoureux d'une étoile» (Acte II - Scène II) en el que probablemente se inspiran:

Portas al cuello la gentil nobleza del heráldico lirio y en la mano el puro corte del cincel pagano, $\mathrm{y}$ en los ojos abismos de belleza.

Hay en tus rasgos acritud y alteza, orgullo endurecido en un arcano, y resulto en mi prez un vil gusano que a un astro empina la bestial cabeza.

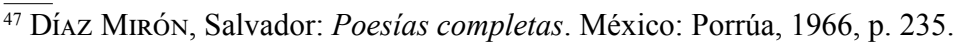


Quiero pugnar con el amor, y en vano

mi voluntad se agita y endereza

como la grama tras el pie tirano.

Humillas mi elación y mi fiereza, y resulto en mi prez un vil gusano que a un astro empina la bestial cabeza ${ }^{48}$.

Díaz Mirón utiliza este recurso en sus sonetos con cierta regularidad; se encuentra de nuevo en el titulado «Audacia» en el que los versos 13 y 14 repiten el 7 y el 8:

y en empinados vórtices pasea el abismo de abajo en el de arriba ${ }^{49}$.

No parece verosímil que Juan Eduardo Cirlot conociese la obra del poeta también mejicano Luis G. Urbina. Pero es de señalar la semejanza de algunas repeticiones en los sonetos de ambos poetas. Véase el titulado «A Thais», de Urbina, que parece un barrunto de los que J. E. Cirlot escribirá un siglo después. La unidad que se repite se prolonga cada vez en una oración de relativo: «mi beso que...»:

Beso tus ojos tristes como suele sus reliquias rezar, en tanto reza, una anciana piadosa. Y tu cabeza que a perfumadas liviandades huele,

beso porque mi beso te consuele, mi beso que es unción y que es tristeza, mi beso que está limpio de impureza, mi beso que no mancha y que no duele.

Yo sé bien que es romántica locura besarte así, con beso que no alcanza a encender la pasión sensual e impura;

mas gusto de juntar, en suave alianza, mi aspiración de amor y de ternura a tu ideal de ensueño y esperanza ${ }^{50}$.

${ }_{48}$ Ibid., p. 195.

${ }^{49}$ Ibid., p. 231.

${ }^{50}$ Urbina, Luis G.: Poesías completas. I. México: Porrúa, 1964, p. 211. 
En «Junto a la fuente de un barrio» el soneto se abre y se cierra con el mismo verso:

Las fuentes viejas y los hombres buenos una emoción me causan parecida; el musgo en el brocal, la piedra hendida, y los perfiles del tazón, morenos.

Mas hace muchos años, de sus senos, brotar se ve, como por una herida, el agua virginal que nos convida con sus cristales limpios y serenos.

Todo en la fuente ha envejecido, menos el agua, la inmortal recién nacida... ( $\mathrm{O}$ Oh corazones de ternura llenos

manad amor, por la incurable herida!) ¡Qué afinidad evocan en mi vida, las fuentes viejas y los hombres buenos! ${ }^{51}$

Un caso curioso de esta misma utilización del primero en el último verso aparece ya en un soneto de Francisco de Figueroa (1536?-1589); es el soneto XXXI que empieza y termina diciendo: «Maldito seas, Amor, perpetuamente» ${ }^{52}$. Puede afirmarse, sin alto riesgo, que los poemas modernistas no lo conocieron. Es posible se encuentren otros casos en la poesía clásica. Y antes, en el soneto 38 del Canzoniere de Petrarca, el primer verso de cada terceto es el mismo: «Et quel lor inclinar ch'ogni mia gioia» ${ }^{53}$.

La repetición de versos puede tener también sus variantes. En su forma más sencilla aparece repitiendo un verso entero en lugares no contiguos del soneto. Alguna vez, se repite el verso final en el soneto siguiente cuando el poema esta construido en dos composiciones. Así en los dos sonetos «A la novia de un poeta», del mismo L. G. Urbina; ambos sonetos tienen el mismo verso final: «su viejo vaso y su taberna oscura» ${ }^{54}$.

Rubén Darío, en el tan conocido «Gaita galaica», de Poema de otoño, da a los tercetos esta forma repetitiva, salvo la variante

\footnotetext{
$\overline{{ }^{51}}$ Ibid., «Junto a la fuente de un barrio», II, p. 185.

${ }^{52}$ FigueroA, Francisco de: Poesía. Edición de Mercedes López Suárez. Madrid: Cátedra, p. 142.

${ }^{53}$ Petrarque, Canzioniere, cit., p. 114.

${ }^{54}$ Ibid., pp. 129-130.
} 
del verso 13. La repetición se ha ampliado de tal manera que cada miembro se repite en el segundo fragmento del verso y la totalidad de los tercetos:
tiempo de ganar, tiempo de perder, tiempo de plantar, tiempo de coger, tiempo de llorar, tiempo de reír,
tiempo de rasgar, tiempo de coser, tiempo de esparcir y de recoger, tiempo de nacer, tiempo de morir.

Ricardo Jaimes Freyre, en «Siempre», abre y cierra el primer cuarteto con el mismo verso, que cierra igualmente el soneto, con la particularidad de recogerlo parcialmente en el verso 10 . El verso 5 reaparece en el en el 9 ( «Vuela sobre la roca solitaria») y, con variante, en el 8 («sobre la adusta roca solitaria.»). Este soneto requiere una lectura detenida:

Peregrina paloma imaginaria
que enardeces los últimos amores;
alma de luz, de música y de flores,
peregrina paloma imaginaria.

Vuela sobre la roca solitaria que baña el mar glacial de los dolores; haya, a tu paso, un haz de resplandores sobre la adusta roca solitaria.

Vuela sobre la roca solitaria peregrina paloma, ala de nieve como divina hostia, ala tan leve

como un copo de nieve; ala divina, copo de nieve, lirio, hostia, neblina, peregrina paloma imaginaria ${ }^{55}$.

En el soneto «Setiembre», de César Vallejo, se encuentra un verso repetido (el 3 en el 7) aunque con distinta puntuación y, además, la misma palabra en rima en los versos 9 y 11. El verso 13 queda blanco y en el conjunto del soneto la distribución de las rimas es aleatoria:

${ }^{55}$ CaIllet Bois, Julio: Antología de la poesía hispanoamericana. Aguilar, 1965, p. 809. 
Aquella noche de setiembre fuiste tan buena para mí hasta dolerme! Yo no sé lo demás; y para eso, no debiste ser buena, no debiste.

Aquella noche sollozaste al verme hermético y tirano, enfermo y triste. Yo no sé lo demás... y para eso yo no sé por qué fui triste... tan triste.

Sólo esa noche de setiembre dulce tuve a tus ojos de Magdala, toda la distancia de Dios y te fui dulce!

Y también una tarde de setiembre cuando sembré en tus brasas, desde un auto, los charcos de esta noche de diciembre ${ }^{56}$.

Manuel Machado recurrió a la epanáfora en los tercetos de su soneto «Ocaso» incluido en Alma:

Para mi pobre cuerpo dolorido, para $m i$ triste alma lacerada, para mi yerto corazón herido,

para $m i$ amarga vida fatigada... ¡el mar amado, el mar apetecido, el mar, el mar y no pensar en nada!...

Anáfora y epanáfora no son privativas del soneto. De la «Elegía a Ramón Sijé», de Miguel Hernández, son estos versos tan conocidos:

Temprano levantó la muerte el vuelo, temprano madrugó la madrugada, temprano estás rodando por el suelo.

No perdono a la muerte enamorada, no perdono a la vida desatenta, no perdono a la tierra ni a la nada.

Nótese que -en el primer terceto citado- la palabra repetida va seguida de verbos acentuados en su sílaba final (levantó, madrugó, estás), o de complementos construidos con el mismo

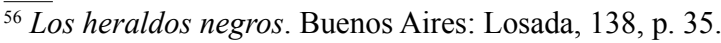


ordenamiento en el segundo terceto (a la muerte, a la vida, a la tierra). También se encuentra en El rayo que no cesa este soneto, con repetición del fragmento inicial en los versos 1 y 9:

Soneto 13:

Mi corazón no puede con la carga de su amorosa y lóbrega tormenta $\mathrm{y}$ hasta mi lengua eleva la sangrienta especie clamorosa que lo embarga.

Ya es corazón mi lengua lenta y larga, mi corazón es lengua larga y lenta... ¿Quieres contar sus penas? Anda y cuenta los dulces granos de la arena amarga.

Mi corazón no puede más de triste: con el flotante espectro de un ahogado vuela en la sangre y se hunde sin apoyo.

Y ayer, dentro del tuyo, me escribiste que de nostalgia tienes inclinado medio cuerpo hacia mí, medio hacia el hoyo.

No es novedad tampoco la repetición de una misma palabra al principio y al final de verso. Es el caso del soneto «Fuera menos penado, si no fuera», igualmente de El rayo que no cesa.

Más próximo en el tiempo, Juan Eduardo Cirlot consigue efectos subyugantes de letanía repitiendo la misma palabra en cabeza de versos contiguos, en preferencias de expresión bebidas quizás en Miguel Hernández. Así en el soneto «A Osiris»:

Repartido en pedazos y en lamentos, repartido en países y en canciones, repartido en lejanos corazones, repartido en profundos monumentos.

Repartido en obscuros sentimientos, repartido en distintas emociones, repartido en palabras y oraciones, repartido y perdido en los momentos.

Heredero del tiempo y del espacio, víctima de transcursos y distancias, ser en seres deshecho y repartido. 
Yo busco tu hermosura y tu palacio, tu boca de rubíes y fragancias para reunirte solo en un gemido.

$\mathrm{O}$ en estos otros que siguen en los que el lector encuentra una impresión de embrujo prolongado. Nótese el efecto de insistencia creciente en el primer terceto, de «cava» a «excava»:

Negra de salvación como dorada roca de soledad entre la sola sombra que me traspasa con su nada, océano del no en que cada ola

es una transparencia exasperada que se rompe y rompiéndose me inmola. Negra de salvación como negada rosa sólo de espinas, sin corola.

Cava en el corazón de la amargura, excava entre mis ojos y mis dientes, desgarra mi amargura de locura;

encontrarás tu voz no pronunciada, encontrarás tus labios ascendentes, encontrarás tu vida y tu mirada ${ }^{57}$.

En la misma serie este otro soneto, produce una impresión de mágicas olas que se alternan: «Señora», «Tus manos, tus brazos; toda tú», «Señora»:

Señora de las sombras, de las horas, señora de las bestias, de las plantas, señora de los cielos donde cantas los astros rutilantes, donde moras.

Tus manos son azules y son santas, tus brazos escarlatas son auroras.

Toda tú son los fuegos que devoras, toda tú son las floras que levantas.

Señora de los vivos, de los muertos, señora de los reinos, de las ruinas, señora de las brasas, de las brisas;

${ }^{57}$ CiRlot, Juan Eduardo: 44 sonetos de amor. Obra poética. Madrid: Cátedra, 1981, p. 286. 
los quemados desiertos ya son huertos cuando en tu resplandor los adivinas.

Y cuando entre relámpagos los pisas ${ }^{58}$.

Obsérvese - ¿será el instinto inconsciente?, ¿será el trabajo afanoso?- el encuentro en situación próxima de sonidos semejantes que, en cierto modo, contribuyen al efecto de la repetición. Así en los versos 7 y 8: «Toda tú son los fuegos» / «Toda tú son las floras» y con mayor evidencia en versos 10 y 11 :

señora de los reinos, de las ruinas, señora de las brasas, de las brisas,

O este otro en el que, sabiamente, el poeta recupera la palabra «Princesa» inicial de los versos 1 a 8 para instalarla en posición de arranque y posición final en el verso 14, así como «La luz de tu tristeza» que reaparece en eco con variante en «La luz de tu belleza»:

Princesa prisionera de la nada, Princesa prisionera de la suerte, Princesa prisionera de la muerte, Princesa del abismo en la mirada.

Princesa de la noche de la espada, Princesa de la noche de lo inerte, Princesa de la noche que se vierte, Princesa sin amor y enamorada.

La luz de tu tristeza de princesa brilla en la claridad de este lamento, es luz que no comienza y que no cesa.

La luz de tu belleza de princesa brilla en la eternidad de este momento, Princesa del horror de ser princesa ${ }^{59}$.

Merece ser citado el soneto "A mi esposa», de Carlos Edmundo de Ory, cuyas repeticiones en cabeza de verso contribuyen también como en los ejemplos de Juan Eduardo Cirlot,

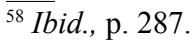

${ }^{59} \mathrm{Ibid}$., p. 288. 
a incrementar el sentimiento de exaltación. Tiene este soneto, además de las repeticiones en cabeza de verso, las situadas en interior de verso, como en 1, 3 y 4 tales «triste cosa», «me armo un lío», «mi esposa»:

Sin ti soy triste cosa y triste cosa

Sin ti me lleno de humo y me extravío

Sin ti me armo un lío y me armo un lío

Sin ti mi esposa busco en ti mi esposa

Contigo la hosca vida es cosa hermosa

Contigo sin dinero compro un río

Contigo nunca lloro y siempre río

Contigo viajo al cielo en mariposa

Yo no te he dado nada y sin embargo

sin darte nada tú me has dado una

una mejilla donde puse un beso

Y tú me has dado eso y me hago cargo

Y tú me has dado el queso de la luna

Y tú me has dado eso eso eso ${ }^{60}$.

Se ha insinuado en las líneas que preceden el efecto de letanía, de embrujo, de magia que estas repeticiones parciales o totales de versos pueden producir y más aún cuando la repetición se encuentra en versos contiguos. Hay en ello además como una intención de exaltación («señora, princesa») que, junto con lo ya señalado, aporta a la poesía moderna un clima, una atmósfera de estremecimiento. $\mathrm{O}$ de trágico instante, como en el caso de la «Elegía a la muerte de Ignacio Sánchez Mejías» ${ }^{61}$.

${ }^{60}$ ORY, Carlos Edmundo de: Soneto vivo, cit., p. 82.

${ }^{61}$ Existen otras modalidades de repetición de elementos del verso, como es el de repetir en idéntica posición, no las palabras, sino las formas gramaticales, empezando los versos con en el mismo tiempo de la conjugación, o con vocablos de grafías próximas. Se reproduce aquí uno de Luis G. Urbina reforzado por la inicial Y seguida de verbo en futuro en cada verso que parece asegura la continuidad en el desarrollo del tema. Es el titulado «Luciérnaga»: «...;Y me abandonarás! Acaso en breve / vas a decirme: adiós. Joven y bella, / después de haber oído mi querella / te irás a donde la ilusión te lleve. / Y quedará en mi vida un rastro leve, / como en la noche el brillo de una estrella, / como en la cima del volcán, la huella / del paso del viajero por la nieve. / Y tejerá la soledad su nido / de silencio, en mi alma. Y el olvido / cubrirá mi memoria con su velo. / Y tú estarás allí como la reja / de una prisión, que entre las sombras, deja / ver un pedazo del azul del cielo». (Poesías 
El Canto general de Pablo Neruda ofrece en algunos de sus poemas, formas paralelísticas que juntan a su valor de exaltación, una impresión de letanía próxima a la devoción, como en estos versos que siguen, en los que Edmond Cros veía «un délire verbal et une expresión chaotique»:
Águila sideral, viña de bruma.
Bastión perdido, cimitarra ciega.
Cinturón estrellado, pan solemne.
Escala torrencial, párpado inmenso.
Túnica triangular, polen de piedra.
Serpiente mineral, rosa de piedra.
Nave enterrada, manantial de piedra.
Caballo de la luna, luz de piedra $[\ldots]^{62}$

Otra variante en la presentación de las formas repetidas es la que ofrece Francisco Pino en su soneto «40 (antígona con pantalón vaquero al espejo)». Consiste la novedad en que los versos están numerados del 1 al 8 en los cuartetos. La numeración en los tercetos remite a los versos anteriores, salvo el número 9 que no tiene antecedente, aunque algunos no respetan íntegramente el verso original:

1 , esta $\mathrm{m}$ al revés que yo me miro

2 , muerte quiere decir y también vida,

3 , es trébol de la tierra impatriotero

4 , y es más silencio mientras es más lira.

5 , entre el azul del pantalón vaquero

6, la $\mathrm{m}$ es v: victoria de mis piernas!

7 , pues yo soy antigona más que antígona,

8 , copa perecedera y fruta eterna.

completas, cit., I, p. 267). Un ejemplo semejante se encuentra en el soneto «Las aves nocturnas» de Manuel José Othon, en el cual las cuatro estrofas comienzan con la preposición A seguida de infinitivo: A infundir / A seguir / A lanzar / A remedar, en Отноn, Manuel José: Poesías y cuentos. México: Porrúa, 1963, pp. 84-85. Son formas expresivas que no es difícil encontrar en la poesía de la posguerra, como en los poemas de Hoguera viva de Manuel Alonso Alcalde (Valladolid: Col. Halcón, 1948), al que pertenecen estos versos del poema «El gran silencio»: «Será cuando de todo lo que existe, / de la hierba que huele -bienamada / del toro de ojos grandes que ya embiste, / de la paloma que ni fue tocada, / de la corza, del ciervo, de la encina, / de la abeja y del mar no quede nada».

${ }^{62}$ NerudA, Pablo: Canto general. Canto II, poema IX. El comentario a este poema se encuentra en Edmon CROS: Introduction à l'étude critique, Textes espagnols. Paris: Armand Colin, 1972, pp. 207-229. 
5 , y en el azul del pantalón vaquero

3 , el trébol de la tierra impatriotero

9 , sin patria alguna ofrézcale al amigo.

6, la m es v: victoria de mis piernas,

8 , copa perecedera y fruta eterna

1 , esta $\mathrm{m}$ al revés que yo me miro!»

Este soneto va seguido de otros tres versos a modo de estrambote que el poeta llama sótano como en otros sonetos suyos. En este caso son los versos siguientes:

sótano

2 , muerte quiere decir y también vida,

4, y es más silencio cuanto más es lira

7 , pues yo soy antigona más que antígoNA ${ }^{63}$.

La sílaba final aparece en mayúsculas como todos los poemas de este conjunto, El júbilo de la última sílaba. Conviene señalar que todas estas diversas «novedades» pueden tener antecedentes en la poesía anterior, aunque los poetas que las emplean, todavía próximos a nosotros, lo hayan ignorado o no hayan tenido conciencia de ello. Tanto que es suficiente bucear en la obra un mismo poeta de épocas precedentes para descubrir múltiples sorpresas. Por ejemplo, el soneto LXI de Boscán repite en los cuartetos expresiones paralelísticas: «Dulce soñar / dulce gozar / dulce no estar / dulce placer». Garcilaso en los dos versos finales de su soneto $\mathrm{V}$ escribe los tan conocidos:

por vos nací, por vos tengo la vida, por vos he de morir y por vos muero.

Francisco de Aldana ofrece una palabra repetida en los tercetos del soneto «Por un bofetón dado a una dama»: la palabra luz utilizada siete veces:

¡Goza, invidiosa $l u z$, goza de aquesto, goza de aqueste daño, oh luz avara, oh luz ante mi luz breve y escasa!;

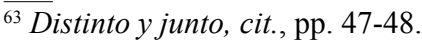


que aún pienso ver, y créeme, luz, muy presto, cual antes a mi $l u z$, serena y clara, y entonces me dirás, $l u z$, lo que pasa.

O este comparativo cual repetido en posición inicial o/e interior de verso se encuentra en «A Cosme de Aldana, su hermano»:

Cual sin arrimo vid, cual planta umbrosa

viuda del ruiseñor que antes solía con dulce canto, al parecer del día, invocar de Titón la blanca esposa,

cual navecilla en noche tenebrosa do el gobierno faltó que la regía, cual caminante que perdió su guía en selva oscura, horrible temerosa,

cual nube de mil vientos combatida, cual ave que atajó la red su vuelo, cual siervo fugitivo y cautivado, cual de peso infernal alma afligida, o cual quedó tras el diluvio el suelo: tal quedé yo sin vos, hermano amado ${ }^{64}$.

Recuérdese igualmente el soneto de Góngora «Mientras por competir con tu cabello» en el que se repite «mientras» en posición inicial de los versos impares de los cuartetos. $\mathrm{O}$, el soneto burlesco de Quevedo «Érase un hombre a una nariz pegado» con anáfora del verbo inicial. Pero el hecho de que algunos poetas anteriores hayan utilizado formas repetitivas no afecta a la intención renovadora de los poetas modernos.

\section{Sonetos con palabras o versos tachados}

No conozco ninguna experiencia anterior a esta de Francisco Pino que se expone a continuación. Se trata de una doble intención que el poeta ofrece en un solo arranque: sonetos de tipo visual en el que algunas palabras son eliminadas, pero dejando suficiente visibilidad para que el lector las reciba e interprete. Y, además, y probablemente es lo más importante, expresar la

$\overline{{ }^{64}}$ Aldana, Francisco de: Poesías castellanas completas. Edición de José Lara Garrido. Madrid: Cátedra, 1985, pp. 188 y 275. 
vocación a reducir la expresión a lo únicamente fundamental, la desnudez sin atuendos: "tal absurdo es mejor que no lo escribas». Son dos sonetos: «El tachar»y «Lo indócil» ${ }^{65}$. Ambos tienen el mismo texto, pero las palabras tachadas en el primero aparecen limpias en el segundo, y las palabras limpias en el primero se han tachado en el segundo. Lo que parece indicar que en el fondo lo que resulta legible en ambos sonetos reconstituye el texto total de un soneto cuya expresión, en fin de cuentas, resulta ser lo esencial: la totalidad de lo expresado. Y también la duda permanente del poeta acerca de aquello que una vez escrito no colma la inquietud de conseguir la expresión fundamental, desnuda, plena:

El tachar

Táchalo todo. Asi, trampuilo quédate: Una luz, un armonio... Que te obligas ar... questa... táchalo pronto, si para librate.

\section{Lo indócil}

fáctor Así, tranquilo quédate. Una luz, un armonio... Que te obligas... que vas a hacer... que intentas poesía... tictoptorto, para librarte.

- Voy a sentirme flor... De prisa, védate, -Voy a sentirme flor... De prisa, védate, tabstrato no lo escribas.

¿Lo hiciste? Táchalo, que esa alegría de asir tu absurdo nadie la comparte.

Aunque al tachar a ti también te taches táchalo. Frás al limbo de las haches, eso inútil que a ti tanto te embebe.

Tacha y retacha, quédate tranquilo;

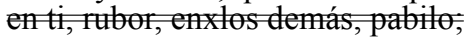
a hermosa noche tu tachar te lleve. tal absurdo es mejor que no lo escribas ¿to hiciste? Táchato, que esa alegría de asir tu absurdo nadie la comparte.

Aunque al tachar a ti también te taches túchalo: Irás al limbo de las haches,

Facha y retacha, quédate tranquilo; en ti, rubor, en los demás pabilo a hermosa noche tu tachar te lleve. eso inútil que a ti tanto te embebe.

En fecha más reciente, Rafael Marín incluye entre sus Sonetos experimentales uno más atrevido que presenta todas las palabras tachadas, dejando solamente visibles las letras de las rimas; un soneto, en suma, sin palabras. La composición respeta la forma aparente del soneto en el que los «versos» se extienden ocupando el espacio que tendrían en su forma visible, con separación incluso de las supuestas palabras desaparecidas. No

${ }^{65}$ Distinto y junto, cit., pp. 357-358. 
se trata ahora de reducir la expresión a su mínima esencialidad, sino de eliminar la expresión y transformarla en algo como su vestigio, su huella. La composición deja de ser «texto» y se cambia en «figura»; ahora lo presentado ya no se lee, se mira. No hay lectura posible sino sólo visualidad.

Evidentemente, se trata de composiciones marginales que aspiran a crear, quizás, una emoción estética ajena a la que procede de la creada por el lenguaje de comunicación. Se le atribuye la denominación de «poesía visual». El «soneto» que se reproduce a continuación tiene como título «Forma en conserva» ${ }^{66}$ :

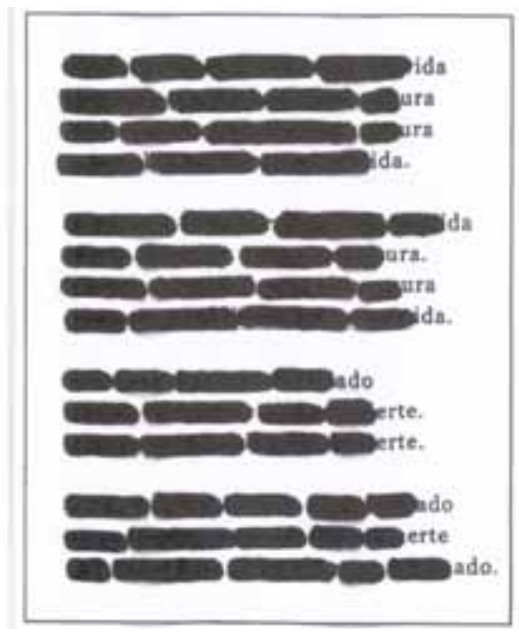

\section{Variaciones tipográficas}

La disposición impresa de los sonetos puede dar lugar a alguna variante respecto a la costumbre de alinear todos los versos a la izquierda. Se encuentran ejemplos, efectivamente, en los que algunas estrofas aparecen sangradas respecto a las otras. No parece haya en ello una aportación al significado de la composición. Un ejemplo se encuentra en Sono il sonetto, Soy el soneto de Mario Ángel Marrodán, en el que todos los sonetos en las dos

$\overline{{ }^{6}}$ MARÍn, Rafael: Sonetos experimentales. Valladolid: Ediciones Tansonville, 2005, p. 57. 
versiones, española e italiana, se han impreso con amplia sangría hacia la derecha del segundo cuarteto y del segundo terceto. También es posible que el autor no haya tenido participación en las decisiones de la editorial. Se ha reproducido más arriba uno de sus sonetos al recordar sus nuevos verbos «sonetear» $\mathrm{y}$ «ensonetarse».

Intencionada es, en cambio, la disposición de palabras o partes de palabras en mayúsculas, en situación de rima o en el interior del verso o en su inicio. Sólo el autor hubiera podido ofrecer el significado de esta modalidad que ahora, ya desaparecido el poeta Justo Alejo, no se alcanza dilucidar. En el apartado Sonetos con disposición no tradicional figura otro del mismo. Se señala en ese apartado que un antecedente ignorado se encuentra en los Sonnets dénaturés de Blaise Candras publicados en 1916. Veamos ahora esta «Peluquería de señoras I»:

Blanca paloma. Y en la mano Ausencia

Olvido Bibelot Blanco, insonORO

bajo el arco del cielo y el tesORO

de las nubes azules sin ESENCIA.

¿Qué buscas en la tarde aquí en PLASENCIA

mirando al SOL en su caudal de ORO

-VIEJO y abandonado- ¿Brilla en CORO

una ESTROFA DE SIGLOS Y PACIENCIA.

Brocal de abril, encaje de la espuma

viento ligero, céfiro suave

que das en alas de alusión a Una

Mente que se despuebla como bruma

ECO de vieja quilla, sueñe nave...

y Soledad Anónima y ... La Lunaaaaaa... ${ }^{67}$

Se reproduce aquí el soneto tal como aparece en la edición de referencia: ausencia de signo final de interrogación iniciada en el verso 5. Son varios los sonetos que presentan esta modalidad de palabras o parte de palabras en mayúsculas que el poeta aplica también a otros poemas.

${ }^{67}$ Poesía, 2, cit., p. 414. 
La disposición tipográfica en mayúsculas en el poema «CATÁSTROFE BANALİ-SIMA DEL HUESO» atañe sólo a la última vocal de cada verso, separada y aislada hacia el margen derecho, como en esta primera estrofa:

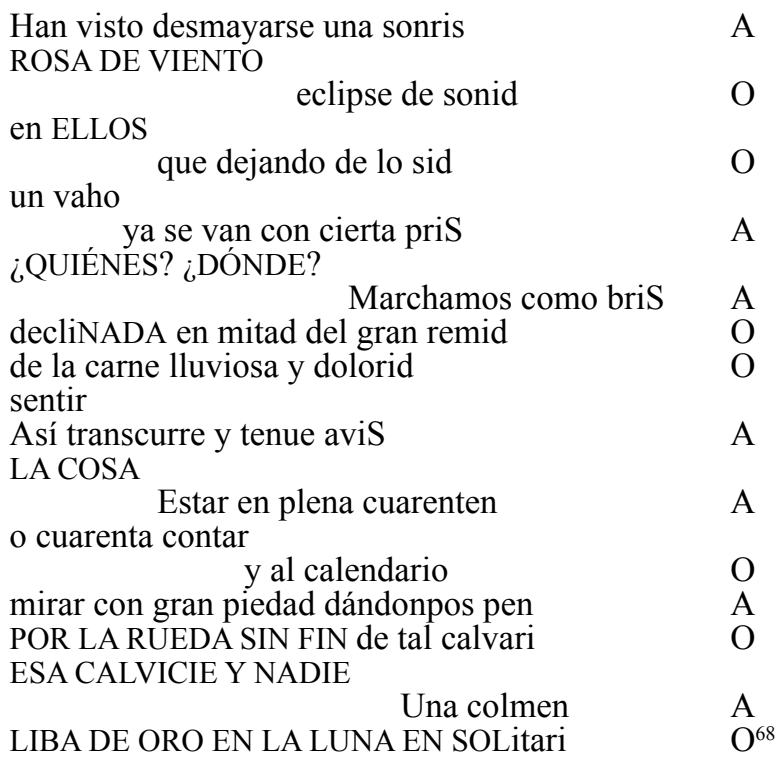

La utilización de mayúsculas en palabras o fragmentos de palabras o la separación de la vocal final, no parecen tener una justificación evidente. No hay en cambio espacio entre las estrofas. Este tipo de composiciones no puede ofrecerse por mera transmisión oral y exige que el lector pueda ver y observar la distribución que el poeta presta a su composición. Poesía que es a la vez tradicional en apariencia y visual.

\section{Variantes recientes del soneto}

Se encuentran en el ya citado libro Sonetos experimentales, de Rafael Marín. Ofrece el poeta en él sonetos hechos a base sólo de vocales o sólo de consonantes, emparentados por lo tanto con los llamados lipogramáticos. Algunos respetan aproximadamente el $\overline{{ }^{68}}$ Ibid., p. 405. 
cómputo endecasílabo, como en el caso del soneto que se copia en sus dos versiones: sin vocales y sin consonantes en páginas enfrentadas del libro (44 y 45). El lector podrá restituir el texto completo cuyo primer verso es «Cuántas noches me he acostado con ganas»:

SONETO VOCALES
Uaa oe e e aoao o aa
e ae e ao u o ueia;
oeo o oi o ua aa
ue o u aaia e aeia.
Uao eeaae o a aaa
uie e aea ue o eia;
u oo e ioaa a eaa
ue e ao u eeo oeia.
I ueo ao e aiaioe
ia a ia e eeia oo
ua iea ue i uia e aoa.
E aioio eeo e oe
e eaa e ue eoe a oo
oo aueo ue e eao eoa.

SONETO CONSONANTES
Cnts nchs m h cstd cn gns
d hcr $1 \mathrm{mr}$ y $\mathrm{t}$ n qrs;
mlst pr drmr cn $\mathrm{n}$ rn
q cn s pt m mlhr.
Cnts dsprtrs pr ls mñns
sfrst l mlstr q y tn;
my pc t mprtb l dsgn
q p mr ts dss cnsntn.
M crp flt d stsfecns
d d rsnt cm
n trr q sn llv gst.
L mtrmn rplt d dns
m djb vr q ntncs y sms
cm qlls q l dsmr dnst.

Es evidente que ante estos ejemplos de supresión de las consonantes o de las vocales, la lectura se cambia en una búsqueda de palabras amputadas y pierde el valor estético y emocional del lenguaje sin que alcance quizá, en estos casos, un valor visual o gráfico.

Menos disconforme con la norma es el que el autor compone a partir de títulos de libros. Marín lo titula «Soneto libresco» en el que cada verso viene a ser una entidad en sí sin relación con el contexto:

El coronel no tiene quien le escriba.

El gran momento de Mary Tribune.

El miedo del portero ante el penalty.

El obsceno pájaro de la noche.

La insoportable levedad del ser.

La sombra del ciprés es alargada.

La tía Julia y el escribidor.

La soledad del corredor de fondo. 
Sesenta y dos: modelo para armar.

Jardín de los senderos que se bifurcan.

Encerrados con un solo juguete.

El laberinto de la soledad.

Historias fingidas y verdaderas.

Retrato del artista adolescente ${ }^{69}$.

El «Soneto al infierno» está compuesto por las palabras que designan los siete pecados capitales. Éste, y los que siguen, entrarían como sonetillos en una clasificación que atendiera al tipo de metro empleado, pero utilizando a la vez la polimetría. Se copia aquí en disposición horizontal por razones de economía de espacio:

primera estrofa: segunda estrofa: tercera estrofa: cuarta estrofa:

soberbia

lujuria

avaricia

envidia segunda
soberbia

lujuria

avaricia

envidia pereza

gula

ira pereza

gula

ira

El que el autor titula «Soneto pluscuamperfecto» es el compuesto por una letra repetida seis veces en cada verso, siguiendo el orden del alfabeto:

primera estrofa: segunda estrofa: tercera estrofa: cuarta estrofa:

aaaaaa

bbbbbb

aaaaaa

bbbbbb aaaaaa

bbbbbb

aaaaaa

bbbbbb $\operatorname{cccccc}$

dddddd

$\operatorname{cccccc}$ dddddd

$\operatorname{cccccc}$

dddddd

Este otro utiliza casi todas las letras del alfabeto dispuestas de dos en dos. Se titula «Soneto literal»:

$\begin{array}{llll}\text { ab } & \text { hi } & \text { op } & \text { uv } \\ \text { cch } & \text { jk } & \text { qr } & \text { wx } \\ \text { de } & \text { lm } & \text { st } & \text { yz } \\ \text { ef } & \text { nñ } & & \end{array}$

En ellos la composición ha dejado de ser significante. Puede que la simetría que presenta el «Soneto pluscuamperfecto» conlleve una intención de armonía visual difícil de dilucidar.

${ }^{69}$ Sonetos, cit, p. 49. 
La última composición del libro es la frase que dice «esto es un intento de soneto», dispuesto a modo de un acróstico, una sílaba para cada verso:

primera estrofa: segunda estrofa: tercera estrofa: cuarta estrofa:

es

to

es

un in

ten

to

de so

ne

to per

fec

to. $^{70}$

Hasta aquí las composiciones que, en ese libro, utilizan letras, sílabas o palabras de la lengua y que, a sabiendas o no del autor, tienen una relación con el movimiento letrista, inventado por Isidore Isou que dio de él la definición siguiente: «Art qui accepte la matière des lettres réduites et devenues simplement elles-mêmes (s'ajoutant ou remplaçant totalement les éléments poétiques et musicaux) et qui les dépasse pour mouler dans leur bloc des œuvres cohérentes $\rangle^{71}$. Se trata pues de independizar el poema de su significado y de utilizar otra forma de significante inhabitual que pretende aportar una coherencia inédita sin relación con lo que el poema tradicional dice o pretende decir. La poesía se distancia así, voluntariamente, del contenido para ceder a una estética visual emparentada con la obra pictórica.

Es posible que estas experiencias de Rafael Marín deriven de la poesía visual de Francisco Pino quien, entre otras muchas manifestaciones consideradas sino ejemplares al menos precursoras, ha dedicado buena parte de su obra a la poesía visual. Ya en su obra Solar (1969) aparece un soneto, con el título de «SON E TO» que se compone de catorce veces la letra E dispuestas en vertical y mayúsculas, añadiendo a la última, pero espaciadas, la letra $\mathrm{h}$ y un signo final de exclamación: «E $\mathrm{h} \quad !\rangle^{72}$

Otros «sonetos» de Rafael Marín, en su mismo libro, prescinden totalmente del lenguaje formando conjuntos de $4+4+3+3$ de

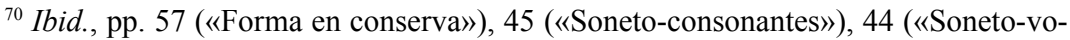
cales»), 41 («Soneto al infierno»), 23 («Soneto pluscuamperfecto»), 18 («Soneto literal») y p. 60.

${ }^{71}$ Bilan lettriste, 1947. El primer manifiesto se encuentra en su obra Principes poétiques et musicaux du mouvement lettriste (1946).

${ }^{72}$ Distinto y junto, 3, cit. p. 135.
} 
objetos diversos: naipes, improntas de manos, bolígrafos, cerillas, una quiniela, etc., formando así como breves ilustraciones en monocromía o polícromía.

\section{El soneto interpolado}

Jacques Roubaud, en un estudio bien conocido, afirma rotundamente que: «Tout sonnet est une unité autonome. Même si un sonnet s'inscrit dans un ensemble, il peut exister seul; il constitue à lui seul un poème autonome, ayant un sens plein.») $\mathrm{Y}$ añade que: «Un sonnet n'est jamais une strophe d'un poème plus étendu. Le caractère quasi-universel de ce trait est un phénomène remarquable ${ }^{73}$.

Un soneto es siempre, efectivamente, un poema autónomo. Sin embargo, también cabe la sospecha de que el lector, o el espectador en el teatro, que no son expertos metricistas, acojan en su lectura o en su escucha, un soneto integrado en un poema dramático, o en un poema no dramático de amplias dimensiones, como unidad estrófica de ese mismo poema. Sería de desear disponer de reacciones de lectores y de espectadores que aportaran su juicio a este propósito.

Desde que el soneto existe, muchos poetas han compuesto conjuntos formados por ese tipo de composición en torno a un tema, amoroso generalmente en los primeros tiempos. Recuerdan Navarro Tomás y Rudolf Baehr algunas de las series modernas de sonetos más conocidas como son las de Salvador Rueda: El friso del Partenón, Amado Nervo: El prisma roto, Leopoldo Lugones: Los doce gozos, Antonio Machado: Los sueños dialogados, Alfonso Reyes: Jornada en sonetos. Y apunta Baehr que, aparte de Zorrilla y Núñez de Arce, Verlaine también podía haber servido de modelo, especialmente en Sagesse. Los sonetos en serie de José Zorrilla son los de su «Roma y Cristo», y los de Núñez de Arce los de su «Crepúsculo vespertino»y «El único día del paraíso»».

Hay igualmente ejemplos de poemas compuestos en sonetos en serie en otras lenguas entre los cuales son los más conocidos

\footnotetext{
${ }^{73}$ RoubAud, Jacques: «La forme du sonnet français de Marot à Malherbe, recherche de seconde Rhétorique». Cahiers de Poétique comparée, 1900, 17, 18, 19, Publications Langues' $O$, Paris.
} 
los de Shakespeare (Shake-Speares Sonnets, 1609), los de Sagesse de Verlaine ya citado, y los de Rilke (Sonetos a Orfeo, 1922).

En nuestros días, basta establecer una llamada en línea para que se ofrezcan series recientes de sonetos, como esas «Vacaciones en seis sonetos encadenados» que aparecen en pantalla, sin nombre de autor, y que respetan la forma tradicional ${ }^{74}$.

El soneto interpolado en el teatro clásico aparece siempre íntegro, recitado por un solo personaje, y nunca fragmentado en diálogo. Generalmente interrumpe una tirada en formas métricas distintas -romances, redondillas, quintillas o décimas- que pueden reanudarse una vez el soneto recitado. Suele aparecer en monólogo de un personaje solo en escena, lo que le da, efectivamente, cierto carácter de expresión autónoma. Pero también pueden encontrarse sonetos contiguos (en El príncipe constante, de Calderón, Fernando recita el famoso soneto «Estas que fueron pompa y alegría» que Antonio Machado juzgó como ejemplo de poesía que no es «palabra en el tiempo»; Fénix le contesta poco después con otro soneto: «Esos rasgos de luz, esas centellas»), o dichos por dos personajes que se ignoran (Acto III de Los embustes de Celauro, de Lope, escena XVIII).

En general, el soneto suele aparecer cuando la intriga ya está avanzada; no así en Peribáñez, del mismo Lope, donde hay dos, el primero ya en la escena II del Acto I: Luján dice «Esto escriben de Medoro», siguiendo el soneto «Reinaldo fuerte en roja sangre baña».

Alguna vez se ha utilizado el soneto como elemento que llega del exterior y viene a anunciar algo inesperado. Así en $E l$ caballero de Olmedo, un corto diálogo en redondillas entre Inés y Leonor (vv. 491-502) se cambia en soneto cuando la primera anuncia: «Leerte unos versos quiero». Y lee el que empieza: «Yo vi la más hermosa labradora». Estos ejemplos no son, naturalmente, exhaustivos.

Si se considera que una comedia es un largo poema, aunque dramático, quizás se pueda plantear la pregunta de si el soneto, interpolado entre otras formas métricas, bruscamente, sin transición ninguna, puede ser percibido como estrofa y es recibido como tal por el espectador.

\footnotetext{
${ }^{74}$ En línea: http://personales.ya.com/emsa/josep/poesia/vacaciones.pdf
} 
Una experiencia más reciente es la que ha realizado Rafael Morales intercalando sonetos en poemas compuestos por diversas formas, incluso sin separación ninguna entre ellas. En su libro La máscara y los dientes, 1962, incrusta sonetos en el poema «La calle». Este poema se compone de un soneto inicial seguido de un romance endecasílabo, así como en el poema «El tranvía» en el que el soneto va seguido de una silva polimétrica en la que aparece una asonancia -áa desordenada. En «La oficina» hay un soneto incrustado entre otras partes de formas diversas. «Amor, dolor» empieza con soneto que continúan sin transición cuatro serventesios y una redondilla. La inclusión de sonetos a manera de estrofas se encuentra igualmente en el libro La rueda y el viento, 1971, del mismo Rafael Morales, cuya primera parte viene a ser un largo poema polimétrico en el que se intercalan tres sonetos seguidos que difieren del resto por su apariencia visual. $\mathrm{Y}$ es de notar que esa utilización del soneto como fragmento integrado en poemas de considerable extensión, no ha sorprendido ni sorprende ni a los tratadistas ni a los lectores. Es probable que otros poetas hayan escrito poemas con sonetos interpolados.

Estas consideraciones no pretenden sino llamar la atención sobre la oportunidad de considerar o no el soneto, en ciertas posiciones dentro de una obra mayor, como una estrofa más del poema en que se encuentra incluido. No se trata de negar el carácter autónomo del soneto, sino sólo de ampliar sus posibilidades cuando, en un conjunto mayor, es utilizado sin solución de continuidad, como partícula del poema.

\section{El soneto, forma fija}

En un soneto publicado en 2004, Enrique Badosa expresa el desdén que sufre esta composición entre los poetas de su época, y cuya primera estrofa dice así:

Hoy la moda abomina del soneto -poco moderno, poco progresista, de derechas quizá, misoneísta-, y me ordenas el riesgo del cuarteto ${ }^{75}$.

${ }^{75}$ Otra obediencia a Violante, Otra silva de varia lección (1950-2002). Valladolid: Fundación Jorge Guillén, Col. Cortalaire 50, 2004, p. 102. 
Hay ahí argumentos de carácter social y político, quizás porque esta composición nos llega asimilada a ideas impregnadas del clasicismo («poco moderno») y también porque el soneto «exaltado» por la Juventud creadora de José García Nieto ha sido la forma más frecuente en la poesía de los primeros años de la posguerra («de derechas quizá»). Badosa se alza contra ese criterio. Como se ha visto en los ejemplos que se citan en este trabajo, no parece que ese desamor del soneto al que se refiere Badosa corresponda a la realidad actual. Más bien puede afirmarse que el soneto mantiene su vitalidad en sus formas clásicas, pese a las numerosas variantes aquí recogidas. La revista actual de poesía Piedra de molino ${ }^{76}$, por ejemplo, presenta en casi todos sus números una página inicial con un soneto referido precisamente a la piedra del molino.

Sí es cierto que las numerosas variantes señaladas en este trabajo provocan la duda de si se puede considerar el soneto aún como una forma fija. Parece se imponen dos definiciones de esta composición: la que recoge las características del soneto ortodoxo, tradicional, clásico, endecasilábico, aconsonantado y distribuido en grupos estróficos de $4+4+3+3$, o sea, dos cuartetos y dos tercetos. Y otra definición menos rigurosa que admite todo tipo de variantes: polimetría, rimas desordenadas, ausencia de rimas, número variable de versos, apariencia tipográfica diversa, sonetos sin una vocal, o sólo compuesto de vocales, o sólo compuesto de consonantes, o con palabras tachadas, o sin palabras, o con la lengua sustituida por figuras, etcétera, y un amplio etcétera.

Será prudente en adelante reservar la denominación de forma fija únicamente para el soneto tradicional y admitir también que otras formas de soneto reclaman también su legitimidad.

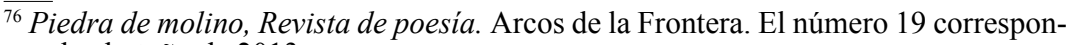
de al otoño de 2013. 